\title{
LITERATURA ADOXADA: \\ AS FORMAS DE ESCRITA POÉTICA DA NEGRITUDE NA COSMOGONIA AFRO-BRASILEIRA
}

Livia Maria Natália de Souza*

RESUMO: Este texto nasce de uma provocação sobre como, enquanto poeta negra, adepta de religião de matriz africana e Teórica da Literatura, compreendo as formas de representação da violência contra pessoas negras - notadamente o genocídio da juventude negra - na minha escrita. Ocupando estes lugares, busquei aqui, a partir de uma metodologia herdada das feministas negras norte-americanas e brasileiras, fazer dialogar estes lugares interpretando, a partir da noção de Literatura Adoxada ou de Literatura de Encantamento, a cosmovisão que a minha literatura estabelece. Para tanto, busquei pensar como a minha vivência dentro do Orixá e a minha filiação a uma qualidade específica de Osun, uma que se faz acompanhar de ègúns, pode ser um operador para analisar o meu próprio lugar de fala. A noção de Literatura Adoxada analisa não apenas a minha escrita, mas é adequada para pensar um enorme número de escritas de autoria negra.

PALAVRAS-CHAVE: Genocídio da juventude negra; Literatura Adoxada; Literatura de Encantamento; Teoria da Literatura.

Nos últimos anos, tenho investido em fazer aprendizagens sobre mim mesma. A principal delas me ensinou que eu posso escrever um texto acadêmico em primeira pessoa. Vivendo dentro da academia etnocêntrica nos últimos vinte anos, fui formada, desde muito jovem, em uma lógica de pensamento que me excluía, mas, ao mesmo tempo, me compelia a entrar, pela porta dos fundos, no seu complexo universo. Precisei, como mulher negra intelectual, me apropriar, a duras penas, do máximo de instrumentais que conseguisse para produzir reflexões sobre objetos que, ou me calavam, ou me sub-representavam.

\footnotetext{
* Professora Adjunta IV da Universidade Federal da Bahia (Ufba). Doutora em Teorias e Crítica da Literatura e da Cultura pela Ufba.
} 
Aprendi a necessidade do distanciamento analítico e, no curso de Letras, no belo campo da Teoria da Literatura, que o discurso ideológico deturpava a beleza do texto. Com o tempo, entendi que não eram todos os discursos que o faziam. Apenas aqueles que pudessem espelhar minha face negra e falar à minha alma e às minhas dores e questionamentos é que eram inviabilizados pela academia como mera sociologia literária, uma vez que a academia branca não reconhece - e ainda hoje resiste em reconhecer - a Literatura Negra como objeto estético.

Dito isso, denuncio o meu desconforto, aprendido em duas décadas, em investir neste duplo gesto: falar em primeira pessoa - sobre mim e minha escrita - e falar sobre esta Literatura Negra que produzo. Denunciado o monstro da minha angústia, ele não desaparece, mas estará desautorizado a partir de agora.

As feministas negras norte e latino-americanas me ensinaram que fazer epistemologia a partir da negritude é permitir-se falar a partir de sua própria experiência, que foi sistematicamente obnubilada pela violência colonial e, deste meu lugar de fala, intento acionar outras forças epistemológicas. No meu caso, trago comigo a presença dos meus Orixás, ancestrais primeiros que me deram o sopro da vida e a intuição.

Assim, peço a benção de meus mais velhos e mais novos e desejo a todas as pessoas que Osun banhe ricamente as nossas vidas com seu abebè dourado, livrando-nos de todo o mal e nos dando a vidência para reconhecer os inimigos.

“Não se diz o nome desta Osun assim, não!”, sobre a poesia de fazer Ègún dançar

Uma das coisas mais curiosas sobre o meu processo de aproximação do Orixá é que venho - por parte das famílias materna e paterna - de árvores genealógicas ligadas à Umbanda carioca e ao Candomblé de matriz ketu baiano. Tenho conexões profundas com os Orixás desde sempre, e incorporo de Osun desde a mais tenra idade. Aos três meses de 
nascida veio a primeira ximba ${ }^{1}$ que Osun me deu: tive uma parada cardíaca derivada de um choque térmico; a babá me tirara do berço quente e me banhou na água fria. Salva pela intuição de minha mãe que, apesar de iniciada muito cedo, renunciou aos seus encargos como Iyalorixá, sobrevivi. Mas Osun passou a me tomar em vários momentos da minha vida, até os dez, doze anos, quando eu era levada à casa de Dona Olegária, uma benzedeira, que suspendia o Santo e me devolvia à consciência:

\section{(...)}

Pisa no meu juízo com seus pés de peixes, naufrágios

e profundezas

Dança bruta e verdadeira no chão de minha alma, prepara meu corpo para ser sua morada: vomito quizilas e fico de novo límpida e casta. (Trecho do poema Abebé Omin, de Agua Negra, 2011, p.35.)

Quando, aos trinta anos, fui finalmente consagrada ao Orixá, o eixo do meu mundo se alterou por completo. Tenho pensado com alguma constância que não posso recuperar o meu sobrenome africano, mas carrego comigo uma Djina, um Orunkò, um nome que me plantou dentro de mim e este nome me diz que sou parte da coroa que adorna e empodera a bela cabeça de Osun, minha Mãe. E este mesmo nome me promete a alegria. Como sabemos, o nome do nosso Orixá é um segredo de vida, portanto, revelo apenas o que este orunkò significa: "coroação da alegria", para afirmar que aprendi muito cedo que alegria de negros é uma alegria guerreira, então, como canta Gilberto Gil, "não me iludo”. A alegria que meu orunkò me promete mais me ensina a sobreviver neste mundo hostil que me banha no congraçamento fácil.

Queria dormir na Água, nas pequenas ondas veludosas da Água doce.

Morar no precipício silente que cresce para baixo, cosendo náufragos.

${ }^{1}$ A ximba, na linguagem do Candomblé da Bahia, conforme conheço, é uma surra disciplinadora, uma espécie de aviso último, urgente, para que o filho ouça a voz de seu Orixá ordenando-lhe alguma coisa. 
(trecho de Poema, de Sobejos do Mar, 2017, p.29.)

Quando fui consagrada a esse Orixá, vinha com o senso comum de Osun como sendo a deusa da beleza, do amor, do ouro e da delicadeza. Mas, para meu espanto, a minha Mãe é uma Osun velha, poderosa feiticeira que se acompanha dos Ėgúns, seres desencarnados, a quem ensinou a dançar. E, mais ainda, dentre as dezesseis qualidades trabalhadas no Ketu da Bahia, ela é tão única, rara e respeitada que não se pode pronunciar o nome dessa Senhora.

No seu mito de fundação, no seu Itan, conta-se que Osun, a essa época, era casada com Ogum. Ele precisava entregar uma grande encomenda de ferramentas e tinha pouco tempo. O que agravava a situação era que os Ėgúns iriam passar pela cidade naquele período, e eles demoravam dias para ir embora. As pessoas temiam horrorosamente essas almas desencarnadas e fechavam suas portas e janelas à sua passagem. A cidade devia estar silente, como se ninguém ali morasse, por isso, Ogun, o ferreiro, não poderia continuar seu trabalho. Osun, corajosa e ardilosa, disse a ele que ele iria continuar sim, que se dava um jeito. A essa altura, o ajudante de Ogun já havia corrido pra casa, amedrontado; então, Osun assumiu o fole, para atiçar o fogo, e ele continuou na forja à todo vapor. Quando os Ėgúns chegaram, ouviram a triste sinfonia de janelas e portas se fechando. Eles sabiam que a cidade era povoada e achavam desrespeitoso o modo como eram tratados pela população. Passavam pela cidade maldizendo-a, e aí estava o motivo do ciclo do medo: o desconhecimento. Ao passarem pela porta da casa de Osun e Ogun ouviram, lá de dentro, algo que parecia uma sinfonia: fon-fon/tin-tin/ fon-fon/tin-tin/ fon-fon/tin-tin.... Eram Osun no fole e Ogun na forja. Curiosamente, os Ėgúns entenderam que se tratava de uma música em sua homenagem, e passaram horas a dançar em frente à casa fechada. Quando a sinfonia parrou, eles bateram na porta e a destemida Osun abriu, sob protestos de Ogun! Os Ėgúns os convidaram a sair, ao que obedeceram. Eles perguntaram: "De quem foi a ideia de tocar esta melodia para nós?”, Osun disse: "Foi minha! Vocês se agradaram?” Ora, claro que sim. E foi tanto que os Ègúns, para agradecer àquela mulher corajosa, os homenagearam com a melodia. Dançaram e atiraram muito ouro e bênçãos sobre Osun e Ogun. 
Esse Itan eu aprendi com Egbomi Cici de Olufan, mais velha do meu terreiro, o Ilê Asè Opo Aganjú, de meu Pai Obaraií, a quem peço, respeitosamente, a benção.

\section{Literatura Adoxada: Asé plantado no ebó de palavras}

A literatura produzida por negras e negros no Brasil tem, desde meados do século XX, a partir da constituição de 1988 e da descriminalização do Candomblé, utilizado a representação das religiões de matrizes africanas como forma de militância e combate ao racismo. Mas, mais que isso, para boa parte da população negra, antes da vigorosa emergência das religiões evangélicas pentecostais e neopentecostais, a convivência com o sagrado-religioso afro-brasileiro fazia, em muitas casas, como na minha, parte da rotina.

Nós nos víamos envolvidos em cenas de cuidado e empoderamento através de banhos, limpezas rituais e benzimentos que nos defendiam do mal e preparava-nos para a luta cotidiana pela existência. Assim meus pais e meus avós foram criados., Assim eu e meus irmãos fomos também. Então, uma das primeiras questões que se coloca é que o acionamento dos Itans e das divindades africanas na nossa literatura não representa uma dimensão do fantástico-maravilhoso, conforme estabelecido pelo campo literário etnocêntrico. Para nós, representar Orixás e outros seres encantados constitui uma política de representação, não um artifício literário que constitui um universo representacional fantástico. Talvez, uma das formas mais relevantes para compreender essa questão seja indagar: em relação a qual eixo representativo a nossa convivência com os Orixás e outras entidades é da dimensão do maravilhoso ou fantástico? De forma alguma! Fazemos uma Literatura Adoxada, a qual gosto também de chamar de Literatura de Encantamento - levando em consideração que chamamos assim entidades como Erês, Caboclos, Pretos e Pretas Velhas... Eles e elas são chamados por nós de encantados, uma vez que constroem, para a nossa vida, o encantamento como abrigo, como espaço, metodologia e estratégia de empoderamento e proteção contra a hostilidade cotidiana do mundo. Para fins de uma possível categorização, a Literatura de encantamento seria mais vinculada à presença da vivência cosmogônica do Asè nos textos, trazendo para a sua cena os poderes dos Orixás, suas histórias 
e feitos mitológicos ou ainda experiências proporcionadas pela vivência no universo encantado dos Orixás. Segundo Henrique Santos ${ }^{2}$, no cômputo da Literatura produzida no Brasil, a literatura de pessoas negras comprometidas com representações da afro-brasilidade relativa a religiões de matriz africana, poderia ser chamada de Literatura Terreiro. De acordo com ele:

O conceito de literatura-terreiro está ligado à ética e estética de textos produzidos desde o corpo negro permeado pela cosmogonia africana e negrobrasileira. Ele está conectado às epistemes que circulam nas religiões afro-brasileiras e prioritariamente refere-se às produções oriundas destes espaços. (SANTOS, 2014)

Assim, declaro que a minha Literatura faz parte de um amplo arcabouço de escritas as quais convenciono chamar aqui e Literatura Adoxada. O adoxu é a consagração do Ori para que ele se torne o fidedigno canal de comunicação entre o iniciado e seu orixá. É feito por uma reunião de elementos secretos que, pilados, são postos em forma de pequeno cone sobre a incisão ritualística da nossa iniciação - cujos detalhes aqui não cabem ser ditos. Trago apenas estrategicamente a noção para que possamos nos afastar do fantástico-maravilhoso e mergulhar na cosmogonia negro-brasileira de matriz africana, rasurando e ampliando o limitado lugar de "representação literária” de eixo etnocêntrico.

No meu caso, o que construo na minha literatura tem enredo ${ }^{3}$ não com a morte (Iku), mas com os mortos, Ėgúns, por causa, certamente, das características da qualidade da Osun que carrego. Dessa forma, descobri que, sem saber, tal como no mito, com meu fole de palavras, coloquei os mortos para dançar. Quando Osun os anima à dança, ela lhes devolve a dignidade, faz justiça à sua força e beleza, e honra a vida que cada um deles teve.

${ }^{2}$ SANTOS, Henrique. Reflexão sobre o conceito de literatura-terreiro. Revista Inventario. $14^{a}$ edição - jan./jun. 2014. DISPONÍVEL em: http://www.inventario.ufba.br/14/Entrevista_Henrique.pdf Acesso em: 12 de outubro de 2018.

${ }^{3}$ Enredo é o que, no ambiente do terreiro, chamamos à ligação ou proximidade de coisas ou contextos aparentemente dispares. 
Dos poemas que escrevi para mortos, o que recebeu maior atenção chama-se "Quadrilha”. Foi publicado no meu segundo livro, Correntezas e Outros Estudos Marinhos, e assim dizia:

\section{Quadrilha}

Maria não amava João,

Apenas idolatrava seus pés escuros.

Quando João morreu,

Assassinado pela PM,

Maria guardou todos os seus sapatos.

(2015. p. 137.)

Escrevi esse poema sob o forte impacto da chacina do Cabula, ocorrida em fevereiro de 2015, quando 12 jovens, todos negros, foram, segundo indicam os laudos, executados. Os jovens tinham, em sua maioria, entre 16 e 22 anos, tendo o mais velho 27 anos. Quase todos eles foram alvejados a menos de 1,5 metros de distância e receberam tiros no rosto, mãos, braço e antebraço. A maioria dos disparos foi feita de cima para baixo, o que reforça a conclusão dos laudos da polícia civil de que o crime tinha traços fortes de execução.

Quase um ano depois, o Movimento Negro de Ilhéus me convidou a publicar poemas numa campanha do novembro negro, gerada a partir de um edital promovido pelo Governo da Bahia. Quando o poema foi divulgado num outdoor na cidade de Itabuna, onde deveria ficar exposto por três meses, houve uma violenta reação da Polícia Militar baiana. Sofri ameaças em minhas redes, via aplicativo de mensagem, passei a temer pela minha vida e segurança e, menos de onze dias depois, o Governo da Bahia ${ }^{4}$, que mentirosamente afirmou não ter dado nenhum tipo de apoio ao projeto, mandou retirar o poema do outdoor. A mão de Iku, representada pela Associação dos Policiais e Bombeiros do Estado da Bahia (ASPRA), coadunada com a bancada da bala, representada por políticos pró-armamento, conseguiu, com a anuência do governador Rui Costa, censurar o poema,

\footnotetext{
${ }^{4}$ Cf. http://g1.globo.com/bahia/noticia/2016/01/escritora-diz-ter-sofrido-censura-em-poema-sobre-morte-denegro-pela-pm.html
} 
e fiquei exposta a ameaças que envolviam, dentre vários gestos de violência, o racismo, a misoginia e a sistemática sugestão de um estupro corretivo por parte de policiais que registravam suas ameaças em mensagens de celular e em minhas redes.

A censura e suas consequências foram tão violentas que, a Freemuse, organização internacional criada em 1998 para denunciar o silenciamento de artistas e oferecer apoio e proteção, divulgou o meu nome no seu relatório Arte sob ameaça - Estatísticas anuais sobre censura e ataques contra a liberdade artística em 20165, como a única brasileira censurada naquele ano entre outros 840 artistas do mundo.

\section{Axexé de palavras: a morte é uma divindade.}

\section{3 minutos*}

Quantas mães ainda vão chorar vendo seus filhos paridos às avessas, pelas armas do Estado? (Sobejos do Mar, 2017.p.63.) ${ }^{6}$

Nós, pessoas negras desse país, arrastamos nossos mortos, desde sempre. Passamos por 400 anos de escravização e mais 130 de pós-abolição, no entanto, sabemos, vivemos numa realidade cotidiana de segregação racial velada, estimulada pelos meios de comunicação, pela literatura, que nos representa de maneira inferiorizada ${ }^{7}$, pela lógica econômica e pelos discursos de democracia racial que apenas aprofundam o fosso entre brancos e negros. Nestes 530 anos de violência racial, as políticas de reparação surgiram tarde. Faz menos de 20 anos que as universidades, concursos públicos e publicidade e propaganda foram

\footnotetext{
${ }^{5}$ Cf. https://revistacult.uol.com.br/home/freemuse-arte-sob-ameaca-2016/

${ }^{6}$ Entre os jovens, de 15 a 29, nos próximos 23 minutos, uma vida negra será perdida e um futuro cancelado. Disponível em: https://vidasnegras.nacoesunidas.org/, acesso em: 21/10/2018.

${ }^{7}$ Cf. Regina e Conceição.
} 
obrigados a reservar vagas para negras e negros, e essa política convive com a desconfiança e desaprovação de muitas pessoas que, ao não compreenderem a necessidade das cotas como política de reparação, imediatamente, findam por não reconhecer os efeitos que 400 anos de escravização tiveram sobre o nosso país. No entanto, no mais das vezes, a maioria das pessoas que não reconhece a necessidade da Lei de $\operatorname{cotas}^{8}$ aprova a redução da maioridade penal, que viola o Estatuto de Criança e do Adolescente (ECA) apenas porque sabem que tal medida não alcançaria seus filhos e filhas, confortavelmente reservados. A redução da maioridade, sabemos, atingirá uma maioria negra, periférica, legalizando a mortandade de jovens negros que já grassa nesse país:

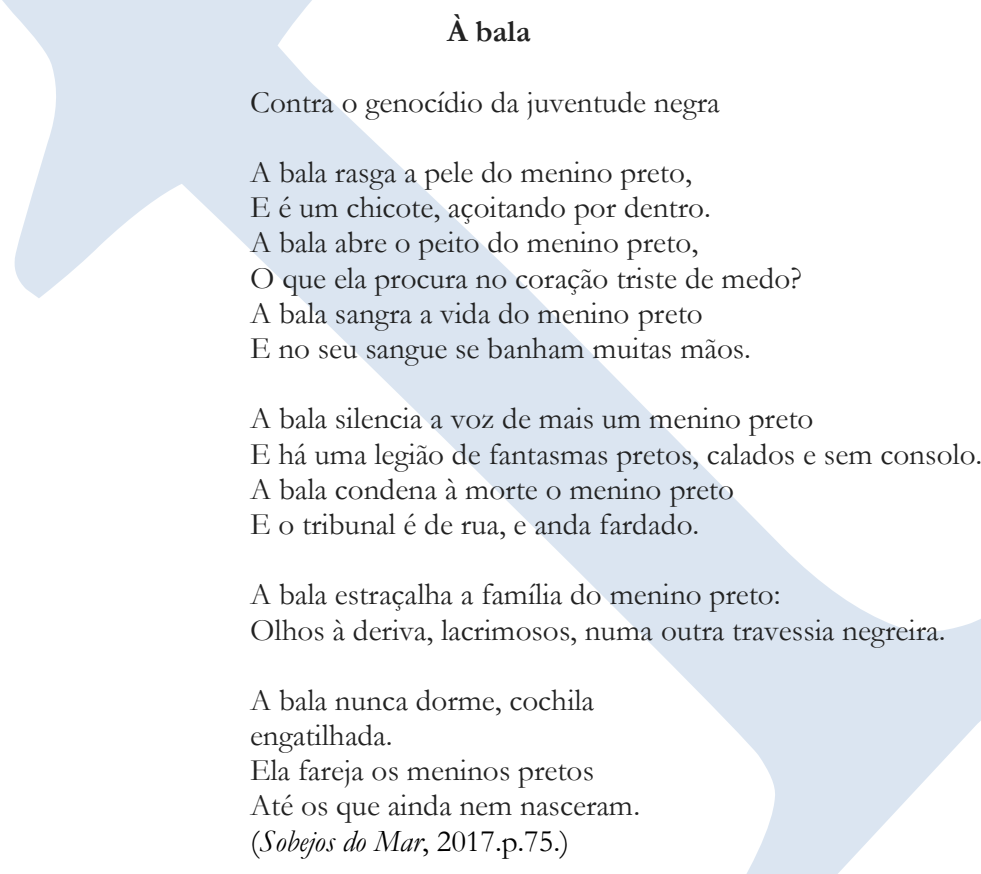

${ }^{8}$ Lei no 12.711, de 29 de agosto de 2012. Cf. http://www.planalto.gov.br/ccivil_03/_ato2011-2014/2012/lei/ 112711.htm. 
Esse poema, mais um que escrevi sob o signo de cantar Eguns, refere-se a outra violência contra jovens negros, ocorrida menos de um ano após a chacina do Cabula, em Salvador. Em novembro de 2015, em Costa Barros, subúrbio do Rio de Janeiro, quatro PMs alvejaram um gol branco no qual estavam cinco jovens negros que haviam saído para comemorar o primeiro salário de um deles. Os jovens Wilton, Wesley, Cleiton, Carlos Eduardo e Roberto, que tinham de 16 a 25 anos, não estavam armados. A perícia averiguou que dos 111 tiros disparados, nenhum veio de dentro do carro; todos os tiros foram disparados pelas armas dos policiais, sendo 81 de fuzil e 30 de pistola. A fala dos pais registra algo da dor que passaram. O discurso fascista que se espalhou pelo Brasil nos últimos anos afirmaria que os jovens eram bandidos, que pessoas de bem não furariam um bloqueio policial. No entanto, é a fala dos pais que nos dizem quem eram os jovens: "Meu filho terminou o curso técnico". "Meu filho fazia inglês". "Meu filho era estudante". "Meu filho estava comemorando o primeiro salário no emprego"9. Dessas, destaco a afirmação da mãe Mônica Correa: "Meu filho foi enterrado nu, porque não era mais um corpo que pudesse ser vestido". Quando confrontamos a fala dolorosa dessa mãe com o que se estabelece na tradição iorubana, compreendemos que um corpo morto é aquele que deve ser cuidado e cultivado, segundo Maria Inez Couto de Almeida:

O cadáver recebia um banho morno, com sabão e esponja. O cabelo da mulher era bem penteado, e o do homem às vezes completamente raspado, ou penteado e escovado. Era costume o filho mais velho estar presente quando o corpo de seu pai era lavado, e ele deveria ser o primeiro a jogar água. Este costume dava ênfase à importância de ter um filho homem como descendente. $\mathrm{O}$ banho do defunto era muito importante, porque eles acreditavam que a pessoa teria que estar limpa para ser admitida na morada dos ancestrais. Se um cadáver não fosse lavado dentro do cerimonial, acreditava-se que ele não teria lugar junto aos ancestrais e o espírito ficaria vagando. Esse espírito era chamado iwin ou iseku. Depois do banho o cadáver era vestido com roupas adequadas, muito bonitas, em geral todo de branco. Se fosse homem, colocava-se um chapéu branco. (ALMEIDA, 2006.p.56.) 
A impossibilidade de reverenciar e sentir a complexa experiência da morte de um filho adoece milhares de famílias no Brasil. Joselita de Souza, mãe de Roberto, 16 anos, morto na chacina de Costa Barros, morreu de "tristeza" pouco mais de seis meses depois do filho, aos 44 anos. Vivemos num país que vomita um corpo negro a cada 23 minutos. Os policiais militares que mataram os cinco de Costa Barros estão respondendo a vários processos e aguardam julgamento. Os do Cabula, recentemente foram absolvidos. Agora, há a perspectiva de federalização do caso para julgamento em nova instância ${ }^{10}$.

Diante disso, cabe perguntar: $\mathrm{O}$ que pode um poema? $\mathrm{O}$ que pode a literatura ante quadro tão violento de desrespeito aos direitos humanos? Um poema pode recolher sujeitos do esquecimento, um poema pode lavar e vestir mortos desimportantes, um poema pode chorar por eles e lhes avisar da importância de sua vida, mais que da sua morte, um poema pode nos devolver a humanidade negada, um poema pode ser afeto na face fria e na sobrevivente, um poema pode ser episteme, pode ser forma de inscrição, recalcar silêncios brancos. Um poema pode pôr os Eguns para dançar, um poema pode ser uma forma de dizer que, mesmo contritos em silêncio, estamos aqui:

\title{
Oriki para Osun
}

O rio se cala, mas há quem não saiba que ele é fundo.

(Água Negra e Outras Águas, 2016.p.75.)

\section{ADOXED LITERATURE: BLACKNESS' POETRY WRITING FORMS IN AFRICAN-BRAZILIAN COSMOGONY}

\begin{abstract}
This text is born of a provocation about how, as a black poet, an adherent of Africanborn religion and Theorist of Literature, I understand the forms of representation of violence against black people - notably the genocide of black youth - in my writing. Occupying these places, I sought
\end{abstract}

${ }^{10}$ Em 28 de novembro de 2018 o STF rejeitou o pedido de federalização do caso da chacina do Cabula. 
here, based on a methodology inherited from the American and Brazilian black feminists, to dialogue with these places by interpreting, from the notion of Adozo Literature or Enchantment Literature, the worldview that my literature establishes. For that, I tried to think how my experience within the Orixá and my affiliation to a specific quality of Osun, one that is accompanied by ègúns, can be an operator to analyze my own place of speech. The notion of Ado Literature analyzes not only my writing, but is adequate to think of a huge number of writings of black authorship.

KEYWORDS: Genocide of black youth; Literature adoxada; Enchantment literature; Literary theory.

\section{REFERÊNCIAS}

ALMEIDA, Maria Inez Couto de/Ifatosin. Cultura Iorubá: costumes e tradições. Rio de Janeiro: Dialogarts, 2006.

NATÁLIA, Lívia. Água Negra. Salvador: Ed. Caramurê, 2011.

NATÁllA, Lívia. Água Negra e Outras Águas. Salvador: Ed. Caramurê, 2016.

NATÁLIA, Lívia. Correntezas e Outros Estudos Marinhos. Salvador: Ed. Ogum’s Toques Negros, 2015.

NATÁLIA, Lívia. Sobejos do Mar.Salvador: Ed. Caramurê, 2017.

SANTOS, Henrique. O arco e a arkhé: ensaios sobre Literatura e Cultura. Salvador: Ogum's Toques Negros, 2016.

SANTOS, Henrique. Reflexão sobre o conceito de literatura-terreiro. Revista Inventario. 14. ed. - jan./jun. 2014. DISPONÍVEL em: http://www.inventario.ufba.br/14/Entrevista_Henrique.pdf Acesso em: 12 de outubro de 2018.

Recebido em: 27/09/2018.

Aprovado em: 22/12/2018. 